\title{
Stochastic modeling for milk production
}

\author{
M.J. Thirunavukkarasu and A. Rajarathinam
}

\begin{abstract}
The present investigtion was carried out to study the trends in India's milk production during the period 1990-91 to 2010-2011 based on fuzzy time series and holt-winters non-seasonal time-series models. Model performances have been carried out based on the model performance criteria such as the lower values of mean square error, variability co-efficient $(\delta)$ and correlation co-efficient ( $r$ ) of the model. It was found that the holt-winters non-seasonal time-series was found suitable to study the milk production trend.
\end{abstract}

KEY WORDS : Window based Fuzzy time series, Mean square error, Variability co-efficient, Holt-Winters non-seasonal model

HOW TO CITE THIS PAPER : Thirunavukkarasu, M.J. and Rajarathinam, A. (2018). Stochastic modeling for milk production. Res. J. Animal Hus. \& Dairy Sci, 9(2) : 26-35 : DOI: 10.15740/HAS/RJAHDS/9.2/26-35. Copyright@ 2018: Hind Agri-Horticultural Society.

M.J. Thirunavukkarasu, Department of Statistics, Manonmaniam Sundaranar University, Tirunelveli (T.N.) India

Email : thirustat10@gmail.com

Associated Authors' :

A. Rajarathinam, Department of Statistics, Manonmaniam Sundaranar University, Tirunelveli (T.N.) India

Email : arrathinam@yahoo.com 